Research Article

\title{
Effect of Nanoparticles and Base Fluid Types on Natural Convection in a Three-Dimensional Cubic Enclosure
}

\author{
Abdellatif Dayf, ${ }^{1}$ M'barek Feddaoui $\mathbb{I D}^{1},{ }^{1}$ Said Bouchta, ${ }^{1}$ Adil Charef, ${ }^{1,2}$ \\ and Houssine El Ihssini ${ }^{3}$ \\ ${ }^{1}$ Laboratory of Energy, Materials and Systems Engineering, Ibn Zohr University, Agadir, Morocco \\ ${ }^{2}$ High School of Technology, Moulay Ismail University, B.P. 3103, Meknes, Morocco \\ ${ }^{3}$ Laboratory of Mechanics, Processes of Energy and Environment, EST, Ibn Zohr University, Agadir, Morocco
}

Correspondence should be addressed to M’barek Feddaoui; m.feddaoui@uiz.ac.ma

Received 21 September 2020; Revised 22 December 2020; Accepted 4 January 2021; Published 18 January 2021

Academic Editor: Mohamed Shaat

Copyright ( $\odot 2021$ Abdellatif Dayf et al. This is an open access article distributed under the Creative Commons Attribution License, which permits unrestricted use, distribution, and reproduction in any medium, provided the original work is properly cited.

Convective heat transfer using nanofluids play an important role in thermal applications such as heat exchangers, automotive industries, and power generation. In this work, a numerical analysis is conducted to examine the heat transfer of nanofluid in three-dimensional differentially heated cavity. The finite volume method-based SIMPLEC algorithm is used to solve the system of the mass, momentum, and energy transfer governing equations. The left and the right vertical side walls of the cube are maintained at constant temperatures $T_{C}$ and $T_{H}$, respectively. The remaining walls of the cube are insulated. Effective thermal conductivity and viscosity of the nanofluid are determined using Brinkman and Maxwell models, respectively. Studies are carried out for three types of nanoparticles and volume fractions of nanoparticles (0-5\%). The effects of two binary liquid mixtures as a base fluid (propylene glycol-water and ethylene glycol-water) are also examined. Results show an enhancement of $13 \%$ for $\mathrm{Al}_{2} \mathrm{O}_{3}-\mathrm{EG}$ in comparison to pure ethylene glycol in the case of $\mathrm{Ra}=10^{3}$. In addition, heat transfer enhancement was increased with the rise of nanoparticle volume fractions.

\section{Introduction}

The heat transfer in the convective mode using nanofluids is found in multitude industrial applications such as devices cooling, heat exchangers, built-in-storage industry, and power generation $[1,2]$. Several studies have been made on nanofluids; their manufacture and their stability are the criteria for choosing the nanofluid as a heat transfer fluid [3-5]. There are number of very recent studies, using conventional numerical methods, on the free convective heat exchange occurring in a $2 \mathrm{D}$ filled with nanofluids. Khanafer et al. [6] elaborate free convection in a cavity inside nanofluid. Their results demonstrated the rate of heat transfer increased with the growth in nanoparticles volume fraction. In another analysis, Mohebbi et al. [7] studied the effect of the presence of a heat source and its location on natural convection in a $\mathrm{C}$-shaped enclosure filled with a nanofluid. Mehryan et al. [8] investigated numerically the free convection of water/Ag- $\mathrm{MgO}$ nanofluids inside porous enclosures using Darcy and LTNE conditions. The results indicate that the dissipation of the $\mathrm{MgO}-\mathrm{Ag}$ nanofluid in water significantly reduces heat transfer through both phases of the porous cavity. Still in natural convection, Ghalambaz et al. [9] conducted a study of thermal transfer of a hybrid nanofluid within a square. They demonstrated that the rate of heat transfer is an increasing function of Rayleigh number and thermal conductivity ratio. Mansour and his collaborators [10] have studied in the numerical form the natural MHD convection in a square cavity filled with the nanofluid with the effect of thermal boundary conditions. Recently, Sameh et al. [11] studied numerically the two heating modes within a triangular porous cavity filled with the nanofluid under the Lorentz force. They showed that the mean and local Nusselt numbers improve with increasing fin height, and this remark is valid in all cases of the study. Similarly, the increase in the percentage of nanoparticles and the heat 
generation/absorption parameter improves both local and mean Nusselt numbers. Ghalambaz et al. [12] numerically investigated the free convective flow and heat transfer of a suspension of nano-encapsulated phase change materials in a square cavity.

The three-dimensional free convection in cavities filled with nanofluids has only been approached by a few researchers; Tric et al.' [13] numerically calculated natural convection in cubic enclosure employ a pseudospectra Chebyshev algorithm resolution supplied by polynomial expansions. In another study, Ravnik et al. [14] examined natural convection in a $3 \mathrm{D}$ filled with nanofluids using a boundary element method (BEM). Ternik [15] investigated free convection of nanofluid (water/Au) in a cubic. The effects of the studied Rayleigh number and solid fraction of nanoparticles on the heat and momentum transport conditions have undergone a thorough analysis.

From the literature reviewed above and to our knowledge, only a few studies deal on three-dimensional nanofluid convection in a cubic enclosure. This motivates the present work by using $\mathrm{CuO}, \mathrm{TiO}_{2}$, and $\mathrm{Al}_{2} \mathrm{O}_{3}$ nanoparticles dispersed in two binary liquid mixtures as a base fluid (propylene glycolwater and ethylene glycol-water) in three-dimensional differentially heated cubic enclosures. The enhancement in heat transfer will be examined versus the type of the base fluid, type, and volume fraction of nanoparticles $(\varphi=0 \%$ to $\varphi=5 \%)$ and Rayleigh number at different locations in the (X, Z) plane.

\section{Mathematical Modelling}

In the physical model as given in Figure 1, simulation domain consists of a cubic enclosure of dimension $H$. The temperatures of the isothermal left and right vertical side walls of the enclosure are $T(0, y, z)=T_{H}$ and $T(H, y, z)=T_{C}$, respectively, with $T_{H}>T_{C}$. The other faces are adiabatic. The cubic enclosure is filled with nanofluid with $\mathrm{CuO}, \mathrm{TiO}_{2}$, and $\mathrm{Al}_{2} \mathrm{O}_{3}$ nanoparticles dispersed in two different base fluids, which are a blend of mixtures by weight of EG (50\%) and water (50\%) for EG-water base fluid and EG (50\%) and PG (50\%) for EG-PG base fluid.

The problem is modelled mathematically based on the following assumptions:

(i) Assuming the flow steady, three-dimensional, laminar, and incompressible

(ii) The thermophysical properties of the nanofluid are assumed to be constant except the density, which varies according to Boussinesq approximation

2.1. Governing Equations. With the above assumptions, the steady natural convection heat transfer in the cube can be described by the governing equations expressed in the dimensionless form [16] as follows:

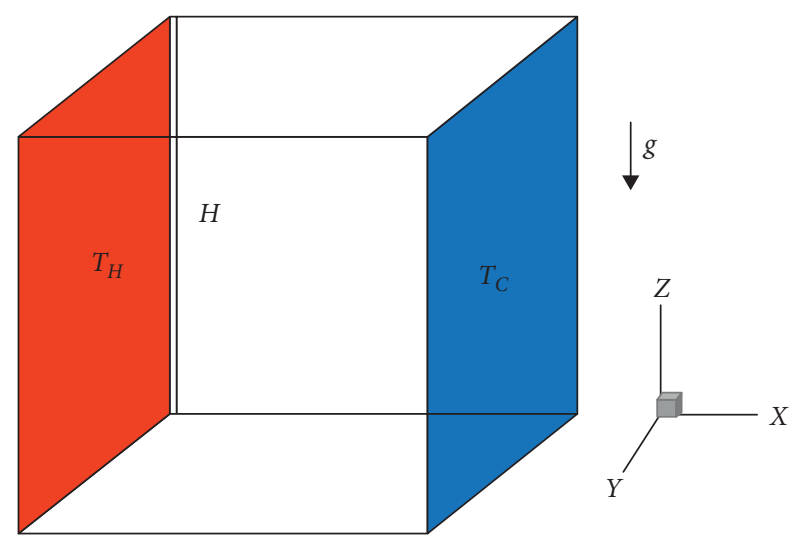

Figure 1: Schematic of the physical problem.

$$
\begin{aligned}
X & =\frac{x}{H}, \\
Y & =\frac{y}{H}, \\
Z & =\frac{z}{H}, \\
U & =\frac{u H}{\alpha_{f}}, \\
V & =\frac{v H}{\alpha_{f}}, \\
W & =\frac{w H}{\alpha_{f}}, \\
P & =\frac{p H^{2}}{\rho_{n f} \alpha_{f}^{2}}, \\
\theta & =\frac{T-T_{\text {ref }}}{T_{H}-T_{C}},
\end{aligned}
$$

where $T_{\text {ref }}=\left(T_{C}+T_{H}\right) / 2$.

$$
\begin{aligned}
\frac{\partial U}{\partial X}+\frac{\partial V}{\partial Y}+\frac{\partial W}{\partial Z}= & 0 \\
U \frac{\partial U}{\partial X}+V \frac{\partial U}{\partial Y}+W \frac{\partial U}{\partial Z}= & -\frac{\partial P}{\partial X}+\frac{\mu_{n f}}{\rho_{n f} \alpha_{f}} \nabla^{2} U \\
U \frac{\partial V}{\partial X}+V \frac{\partial V}{\partial Y}+W \frac{\partial V}{\partial Z}= & -\frac{\partial P}{\partial Y}+\frac{\mu_{n f}}{\rho_{n f} \alpha_{f}} \nabla^{2} V \\
U \frac{\partial \mathrm{W}}{\partial \mathrm{X}}+\mathrm{V} \frac{\partial \mathrm{W}}{\partial \mathrm{Y}}+\mathrm{W} \frac{\partial \mathrm{W}}{\partial \mathrm{Z}}= & -\frac{\partial \mathrm{P}}{\partial \mathrm{Z}}+\frac{\mu_{\mathrm{nf}}}{\rho_{\mathrm{nf}} \alpha_{\mathrm{f}}} \nabla^{2} \mathrm{~W} \\
& +\frac{(\rho \beta)_{n f}}{\rho_{\mathrm{nf}} \beta_{\mathrm{f}}} \operatorname{Ra} . \operatorname{Pr} . \theta
\end{aligned}
$$


TABLe 1: Thermophysical properties of propylene glycol, ethylene glycol, water, $\mathrm{Al}_{2} \mathrm{O}_{3}, \mathrm{CuO}$, and $\mathrm{TiO}_{2}$ nanoparticles at $25^{\circ} \mathrm{C}$.

\begin{tabular}{lccccc}
\hline Physical properties & Water & Ethylene glycol & Propylene glycol & $\mathrm{CuO}$ & $\mathrm{Al}_{2} \mathrm{O}_{3}$ \\
\hline $\mathrm{Pr}$ & 6.2 & 152.19 & 471.24 & - & - \\
\hline$\rho\left(\mathrm{kg} / \mathrm{m}^{3}\right)$ & 997.1 & 1110.27 & 1031.18 & 6510 & 3970 \\
$C_{P}(\mathrm{~J} / \mathrm{kg} . \mathrm{K})$ & 4179 & 2415.67 & 2518.42 & 540 & 7250 \\
$k(\mathrm{~W} / \mathrm{m} . \mathrm{K})$ & 0.613 & 0.253 & 0.2 & 18 & 465 \\
$\beta \times 10^{-5}(1 / \mathrm{K})$ & 21 & 65 & 73 & 0.85 & 0.85 \\
$\alpha \times 10^{-7}\left(\mathrm{~m}^{2} / \mathrm{s}\right)$ & 1.47 & 0.947 & 0.7713 & - & - \\
\hline
\end{tabular}

$$
U \frac{\partial \theta}{\partial Y}+V \frac{\partial \theta}{\partial Y}+W \frac{\partial \theta}{\partial Z}=\frac{\alpha_{n f}}{\alpha_{f}} \nabla^{2} \theta
$$

The Prandtl Pr number and the Rayleigh Ra number are established according to the following formulas:

$$
\begin{aligned}
& \mathrm{Ra}=\frac{g \beta_{\mathrm{f}} \mathrm{H}^{3}\left(\mathrm{~T}_{\mathrm{H}}-\mathrm{T}_{\mathrm{C}}\right)}{\vartheta_{\mathrm{f}} \alpha_{\mathrm{f}}}, \\
& \operatorname{Pr}=\frac{\vartheta_{\mathrm{f}}}{\alpha_{\mathrm{f}}} .
\end{aligned}
$$

In this study, we are treating with a base fluid composed of two different liquids. As mentioned earlier, the base fluids are a blend by weight of EG (50\%) with water $(50 \%)$ or EG (50\%) with PG (50\%). The thermophysical properties of EG, PG, and water are given in Table 1. The corresponding volume fraction of each weigh percentage is calculated to determine the mixture of any propriety $\xi$ such as density, specific heat, thermal expansion coefficient, and thermal conductivity (Abu-Nada and Chamakha [17]).

For EG-water mixture, the mixture of property $\xi$ is evaluated as

$$
\xi_{m}=0.473 \xi_{\mathrm{EG}}+(1-0.473) \xi_{\text {water }} .
$$

For the mixture PG-water, the property of mixture $\xi$ is evaluated as

$$
\xi_{\mathrm{m}}=0.481 \xi_{\mathrm{PG}}+(1-0.481) \xi_{\text {water }},
$$

where the density, heat capacity, and thermal expansion coefficient of the nanofluid can be acquired from the following equations (Oztop and Abu-Nada [18]):

$$
\begin{aligned}
\rho_{n f} & =(1-\varphi) \rho_{m}+\varphi \rho_{p}, \\
\left(\rho c_{p}\right)_{n f} & =(1-\varphi)\left(\rho c_{p}\right)_{m}+\varphi\left(\rho c_{p}\right)_{p}, \\
(\rho \beta)_{n f} & =(1-\varphi)(\rho \beta)_{m}+\varphi(\rho \beta)_{p} .
\end{aligned}
$$

The dynamic viscosity of the liquid mixture is calculated using the equation of Charif and Daif [19]:

$$
\mu_{\mathrm{m}}=\left[\sum_{\mathrm{i}=1}^{2} X_{1, \mathrm{i}}\left(\mu_{1, \mathrm{i}}\right)^{(1 / 3)}\right]^{3}
$$

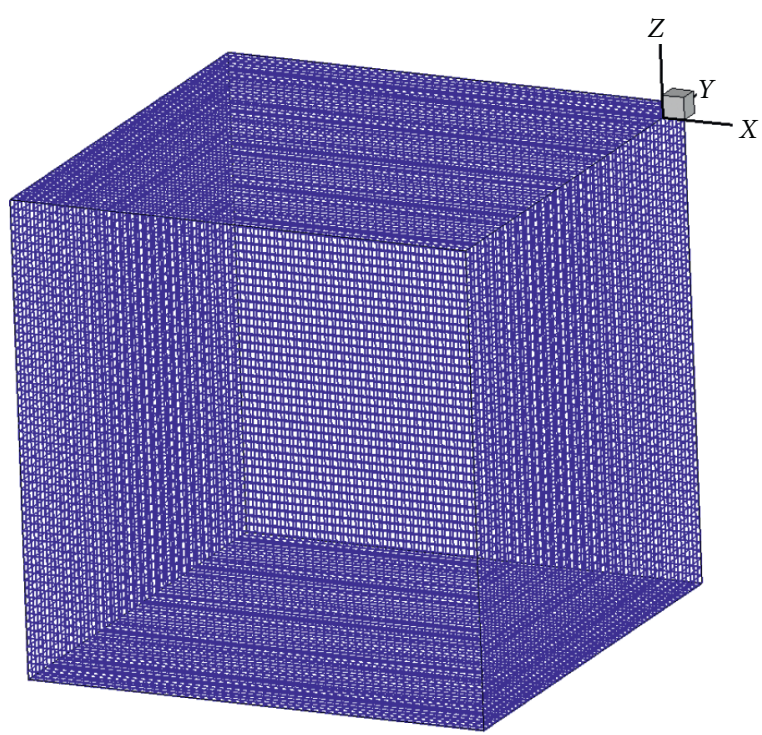

FIGURE 2: Mesh used in 3D cavity.

TABle 2: Grid independence study, $\mathrm{Ra}=10^{5}, \varphi=5 \%$.

\begin{tabular}{lc}
\hline Grid size & $\mathrm{Nu}_{\mathrm{avg}}$ \\
\hline $21 \times 21 \times 21$ & 5.060 \\
$31 \times 31 \times 31$ & 4.832 \\
$41 \times 41 \times 41$ & 4.745 \\
$51 \times 51 \times 51$ & 4.701 \\
$61 \times 61 \times 61$ & 4.674 \\
$71 \times 71 \times 71$ & 4.655 \\
$81 \times 81 \times 81$ & 4.635 \\
\hline
\end{tabular}

TABLE 3: Comparison of present numerical results for the average Nusselt number with other authors.

\begin{tabular}{lcccc}
\hline Ra & $10^{3}$ & $10^{4}$ & $10^{5}$ & $10^{6}$ \\
\hline Present study & 1.073 & 2.077 & 4.373 & 8.698 \\
Tric et al. [13] & 1.070 & 2.054 & 4.337 & 8.641 \\
Ravnik et al. [14] & 1.071 & 2.056 & 4.343 & 8.679 \\
Ternik [15] & 1.071 & 2.049 & 4.327 & 8.627 \\
Fusegi et al. [24] & 1.085 & 2.100 & 4.361 & 8.770 \\
Peng et al. [25] & 1.075 & 2.085 & 4.378 & - \\
Lo et al. [26] & 1.071 & 2.054 & 4.333 & 8.666 \\
\hline
\end{tabular}




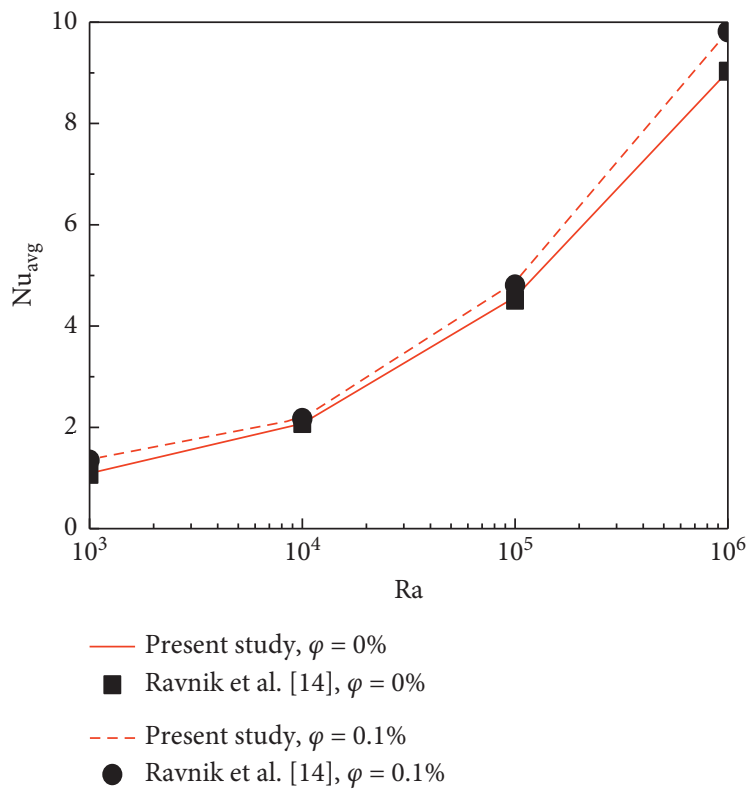

FIGURE 3: Comparison of the average Nusselt numbers in our results with the results of Ravnik et al. [14] for $\mathrm{Al}_{2} \mathrm{O}_{3}$-water nanofluid.

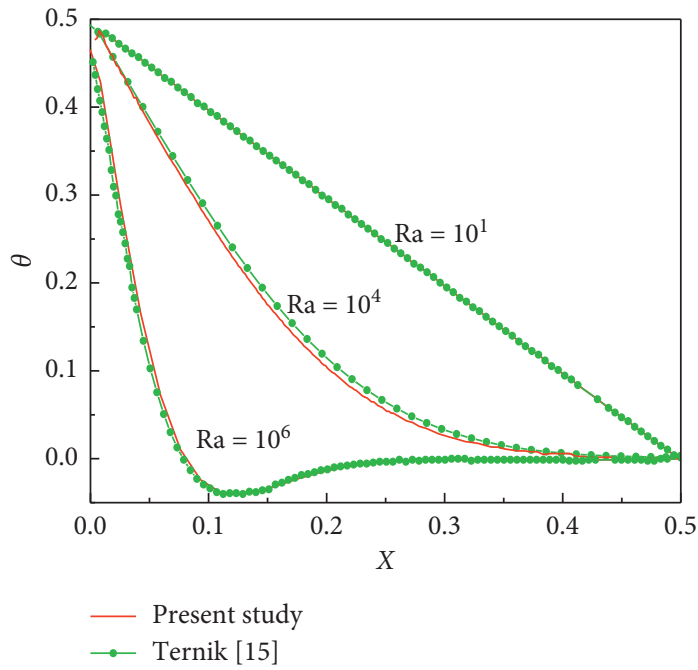

(a)

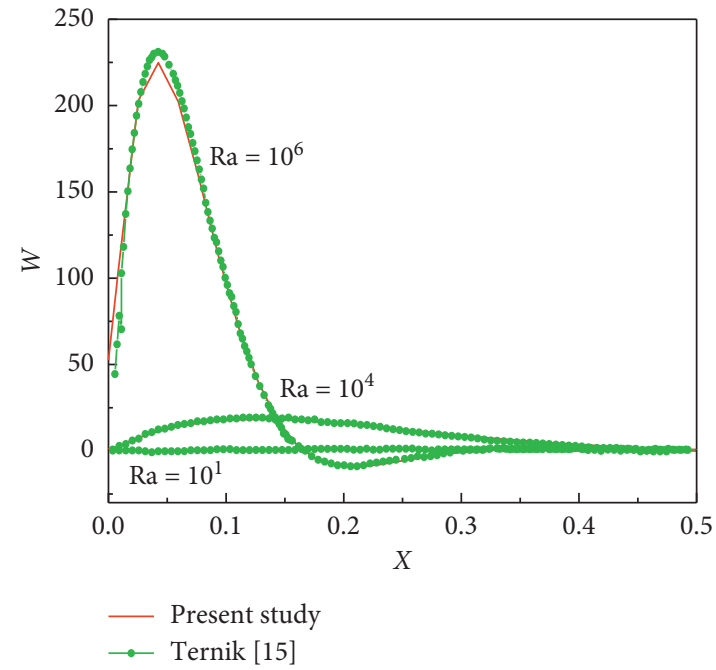

(b)

Figure 4: (a) Variation of dimensionless temperature $\theta$ and (b) dimensionless vertical velocity $\mathrm{W}$ at $Y=0.5$ and $Z=0.5$ plane.

where $X_{1, i}$ is a weigh percentage of each component $i$ of the liquid mixture.

The viscosity of the nanofluid is obtained by the Brinkman model [20].

$$
\mu_{\mathrm{nf}}=\frac{\mu_{\mathrm{m}}}{(1-\varphi)^{2.5}} .
$$

The effective thermal conductivity is obtained by the Maxwell-Garnett model [21].

$$
\frac{K_{\mathrm{nf}}}{K_{m}}=\frac{K_{p}+2 K_{m}-2\left(K_{m}-K_{p}\right) \varphi}{K_{p}+2 K_{m}+\left(K_{m}-K_{p}\right) \varphi}
$$

The boundary conditions for equations (2)-(6) are

$$
\begin{aligned}
& U=V=W=0, \quad \text { on all the walls, } \\
& \theta=1, \quad \text { for } X=0, \\
& \theta=0, \quad \text { for } X=1,
\end{aligned}
$$

$$
\begin{aligned}
& \frac{\partial \theta}{\partial Y}=0, \quad \text { for } Y=0 \text { and } Y=1, \\
& \frac{\partial \theta}{\partial Z}=0, \quad \text { for } Z=0 \text { and } Z=1 .
\end{aligned}
$$

The local Nusselt number is established as follows: 

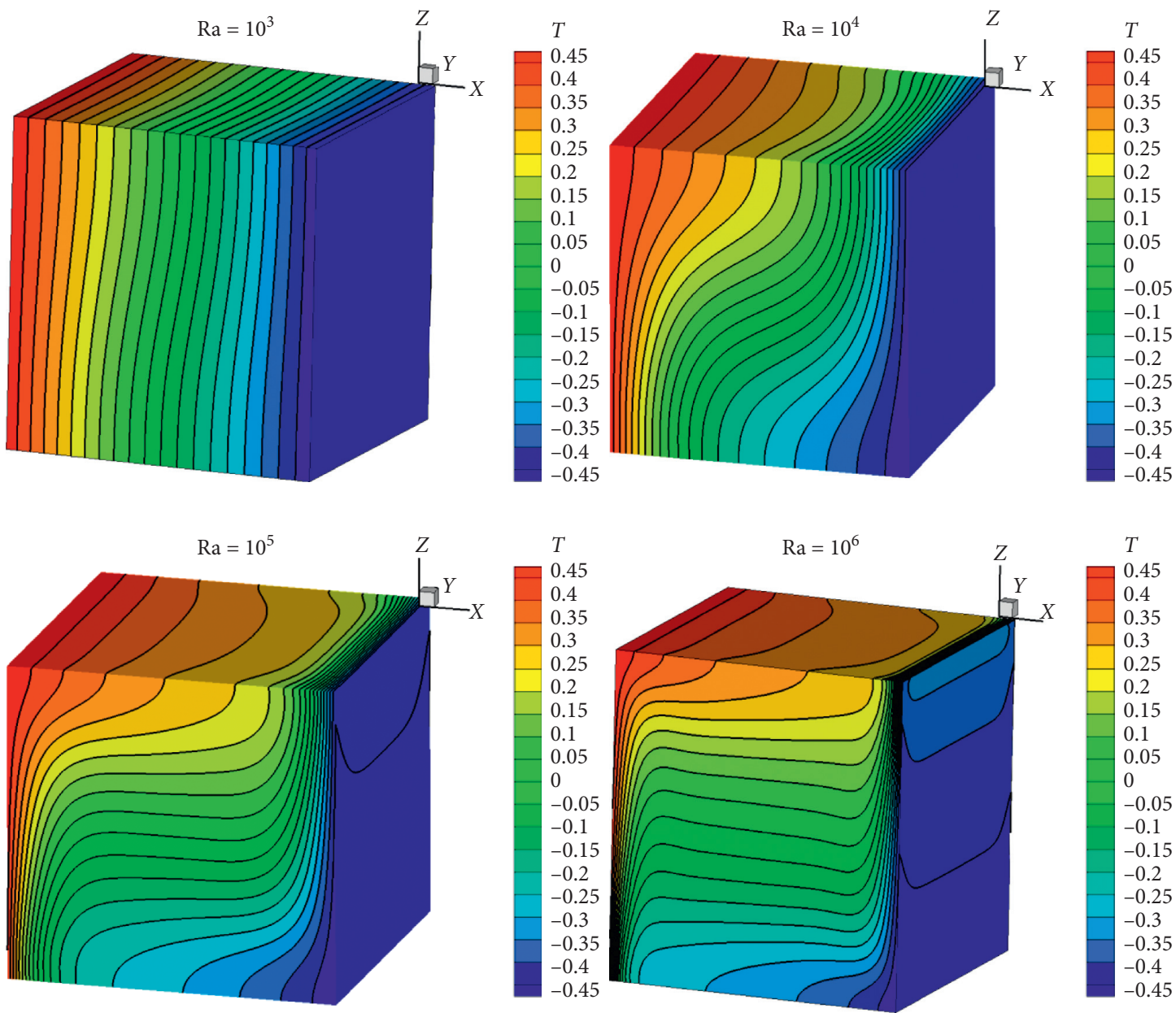

FiguRe 5: 3D isotherms for different Rayleigh and $\varphi=5 \%$ (water- $\mathrm{Al}_{2} \mathrm{O}_{3}$ ).

$$
\mathrm{Nu}_{l}(X, Y, Z)=-\frac{k_{\mathrm{nf}}}{k_{f}}\left(\frac{\partial \theta}{\partial X}\right)_{X=0} .
$$

The average Nusselt number is given as

$$
\mathrm{Nu}_{\mathrm{avg}}=\int_{0}^{1} \int_{0}^{1} \mathrm{Nu}_{1} \mathrm{dZdY} .
$$

The normalized Nusselt number is given as

$$
\mathrm{Nu}_{\mathrm{avg}}^{*}=\frac{\mathrm{Nu}_{\mathrm{avg}}(\varphi)}{\mathrm{Nu}_{\mathrm{avg}}(\varphi=0)} .
$$

\section{Numerical Approach}

The governing equations (2)-(6) in the dimensionless form are linearized by the finite volume method [22]. The resulting set of discretization equations can be cast into a tridiagonal matrix equation and solved iteratively using the TDMA algorithm. The SIMPLEC algorithm is used for the treatment of the velocity-pressure coupling [23]. The numerical solution adopted in this work was implemented by an in-house code in FORTRAN language. The criterion of convergence of the numerical solution is based on the absolute normalized residuals of the equations that were summed for all cells in the computational domain. The normalised global residual $\widehat{R}_{N}^{\varnothing}$ for flow variable $\varnothing$ after $k$ iterations is given as follows:

$$
\left(\widehat{R}_{N}^{\varnothing}\right)^{(k)}=\frac{\sum_{i=1}^{M}\left|\left(\sum_{\mathrm{nb}} a_{\mathrm{nb}} \varnothing_{\mathrm{nb}}\right)_{i}^{(k)}+b_{i}^{(k)}-\left(a_{p} \varnothing_{p}\right)_{i}^{(k)}\right|}{\sum_{i=1}^{M}\left|\left(a_{p} \varnothing_{p}\right)_{i}^{(k)}\right|},
$$

where $\varnothing$ represents the variable $(U, V, W, \theta, P)$.

The convergence is considered as being achieved when the largest residual of all variables falls below $10^{-6}$ at all grid points.

The essential steps constituting the SIMPLEC algorithm are the following:

(1) Initialization of the pressure field $P^{*}$

(2) Solve the momentum equations to get the velocity field

(3) Solve the equation of pressure correction $P^{\prime}$

(4) Correct the pressure $P=P^{*}+P^{\prime}$

(5) Correct the velocities $(U, V, W)$

(6) Solve the energy equation for temperature $\theta$

(7) Consider the corrected pressure as the new estimated pressure value; go back to step 2 and repeat the entire 



Isotherms

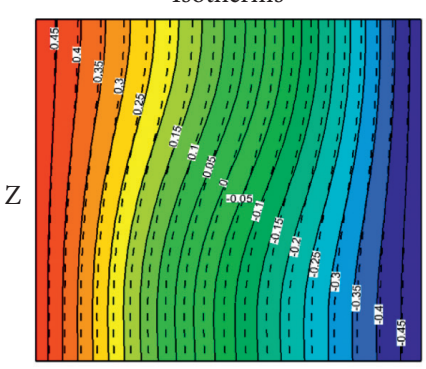

$X$

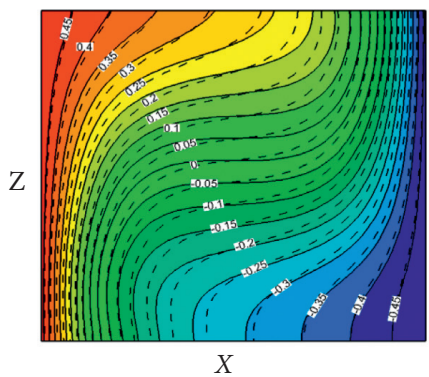

X

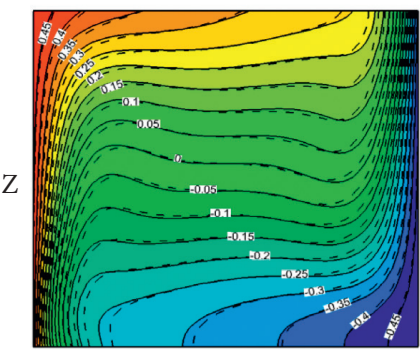

$X$

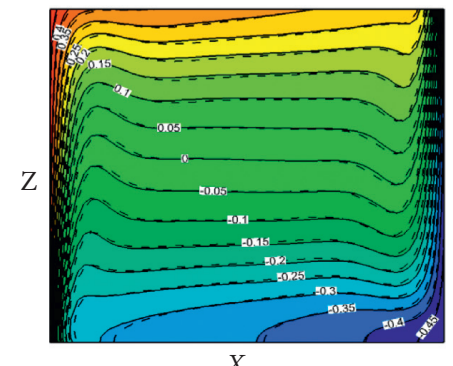

X

FiguRE 6: Streamline (left) and isotherms (right) for water (_) and nanofluid (water- $\mathrm{Al}_{2} \mathrm{O}_{3}$ ) (----) for different Rayleigh numbers, $\varphi=5 \%$ in plane $Y=0.5$.

procedure until you reach the convergence of the solution.

3.1. Grid Independence. A grid independence study is performed by generating five different grid sizes. A uniform grid system is used as shown in Figure 2. The grid refinement tests were carried out to ensure the independence of the calculations (Table 2). According to the obtained results, it is found that in grid sizes ranging from $21 \times(21 \times 21)$ to $81 \times(81 \times 81)$, the difference in the average Nusselt number is less than $4 \%$. Accordingly, to optimize CPU resources with an acceptable level of accuracy, all parametric runs are performed with the $61 \times(61 \times 61)$ grid. In the case of
$\mathrm{Ra}=10^{5}$ and nanoparticles volume fraction $\varphi=5 \%$, the computational CPU time is 2952 seconds.

3.2. Code Verification. To validate our in-house computer code, the obtained results were compared to those from the available benchmark data by Fusegi et al. [24], Tric et al. [13], Peng et al. [25], Lo et al. [26], Ravnik et al. [14], and Ternik [15] for free convection of air in a cube at the Rayleigh number between $10^{3}$ and $10^{6}$. The comparisons between the present results and the corresponding benchmark results are summarized in Table 3. As noted in table, there are appropriate matches between our simulations and those obtained by other researchers. 

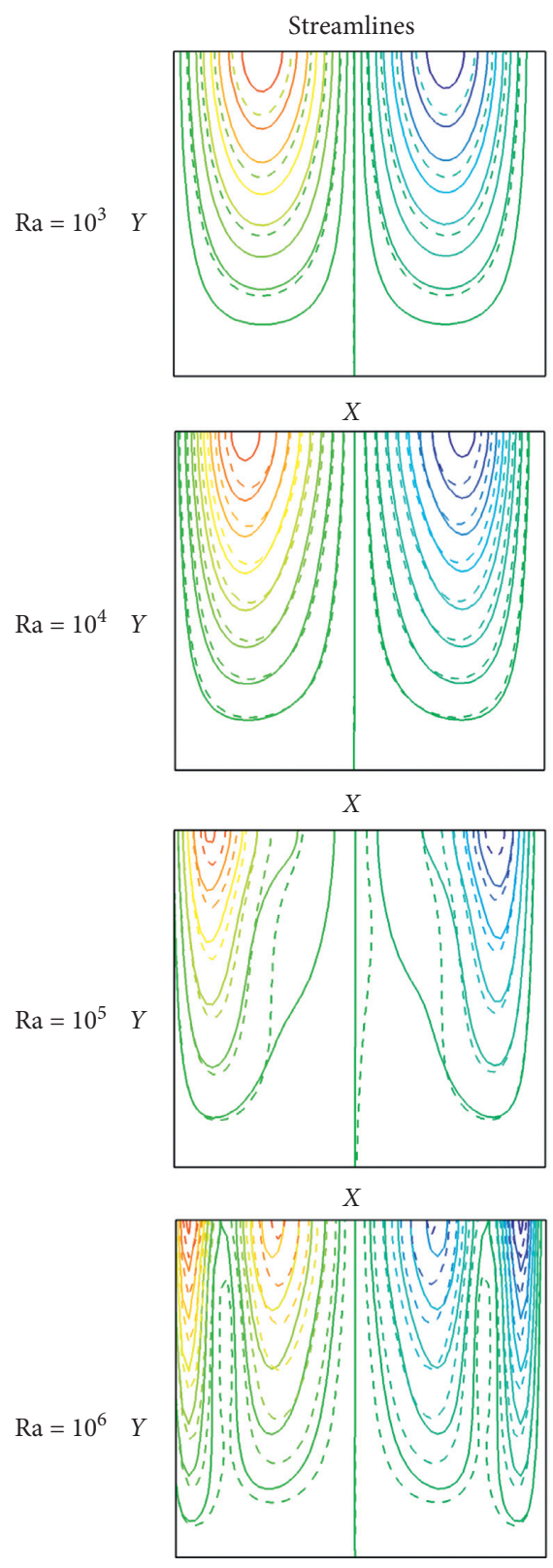

$X$

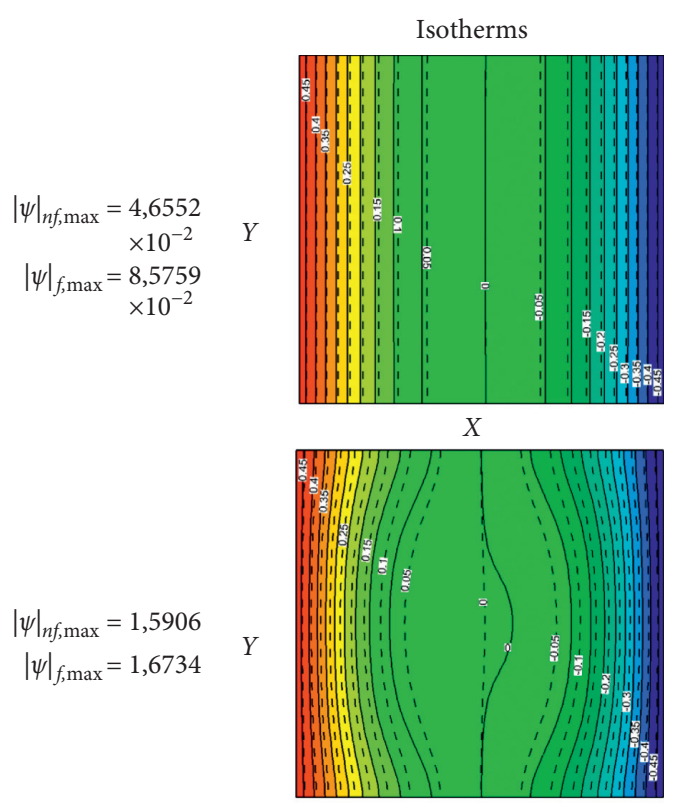

$X$
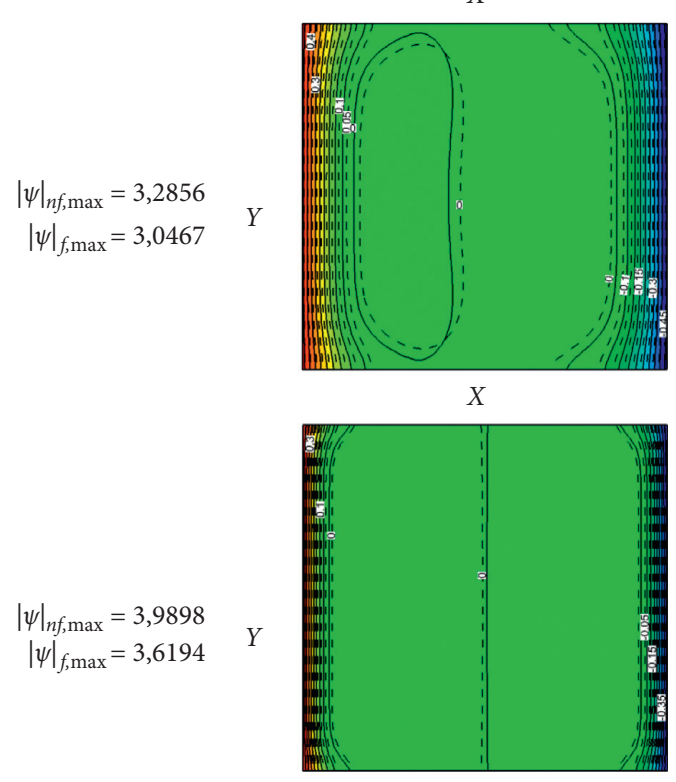

$X$

FiguRE 7: Streamline (left) and isotherms (right) for water (_) and nanofluid (water- $\mathrm{Al}_{2} \mathrm{O}_{3}$ ) (----) for different Rayleigh numbers, $\varphi=5 \%$ in plane $Z=0.5$.

The comparison is carried out also between the present prediction and those of Ravnik et al. [14] in the case of natural convection of nanofluid (water $/ \mathrm{Al}_{2} \mathrm{O}_{3}$ ) in a cubic cavity. Figure 3 illustrates the average Nusselt number of the heat wall at different Rayleigh numbers. The solutions agree well between the two studies, and the discrepancies are less than $1.86 \%$.

The variation of nondimensional vertical velocity $W$ and nondimensional temperature $\theta$ for natural convection of nanofluid (water/Au) in a cubic enclosure $(R a=10$, $\left.10^{4}, 10^{6}\right)$ is presented in Figure 4 and compared with the results of Ternik [15]. It is clear that the present simulations are also in good accord, where the difference is about $1.81 \%$.
According to these successful comparisons, the present numerical code is considered to be suitable for the present investigation.

\section{Results and Discussion}

Figure 5 shows the temperature distribution in the threedimensional cavity for different Rayleigh numbers. The figure shows that the fluid moves from the hot wall to the cold wall. Therefore, the heat transfer rate is permanently maintained in the cavity. The thermal field is marked by strong thermal gradients on the active walls, which means 

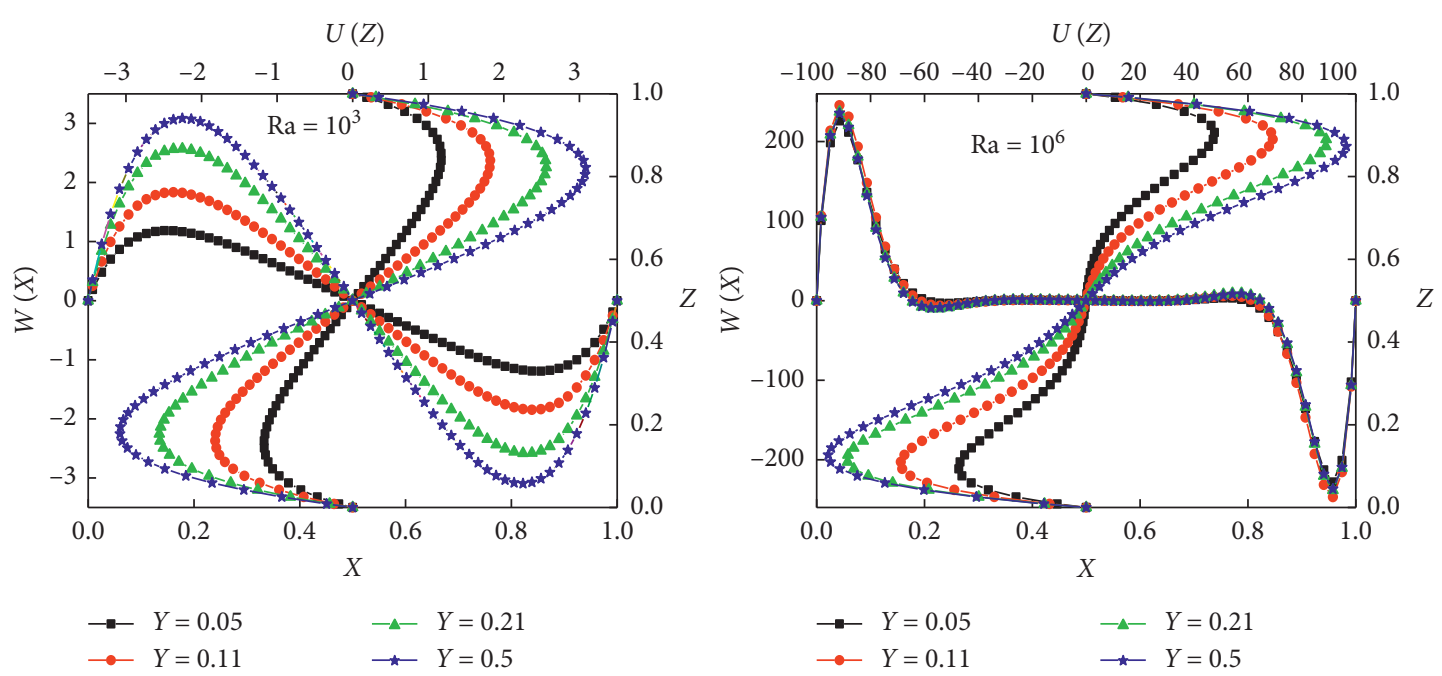

Figure 8: Velocity profiles $U(Z)$ and $W(X)$ along the midpart of the cube for various values of $Y$ and $\mathrm{Ra}=10^{3}$ and $10^{6}$ for water- $\mathrm{Al}_{2} \mathrm{O}_{3}$ nanofluid at $\varphi=5 \%$.

that the heat transfer takes place largely by convection $\left(\mathrm{Ra}=10^{5}, 10^{6}\right)$.

Figure 6 illustrates the temperature fields (right) and the streamlines (left) for the nanofluid (water- $\mathrm{Al}_{2} \mathrm{O}_{3}$ ) in the plane $Y=0.5$ with a volume fraction $\varphi=5 \%$ at the Rayleigh number between $10^{3}$ and $10^{6}$. The results of the pure fluid (water) are also presented in the same figure for comparison purposes and to highlight the effect of the addition of the nanoparticles on the dynamic and thermal fields. The figure clearly shows that the flow structure is characterized by the presence of two cells occupying almost the entire cavity for different Rayleigh number values. According to the streamlines values shown in the figure, the flow of the pure fluid is stronger than that of the nanofluid for $\mathrm{Ra} \leq 10^{4}$; while for $\mathrm{Ra} \geq 10^{5}$, the trend is reversed and the flow of the nanofluid is more intense than that of the pure fluid. This behaviour is due to an enhancement of the viscosity and buoyancy force which depends on the density for nanofluids. Hence, at low and moderate Rayleigh number values, the driving force decreases for the pure fluid and the nanofluid is dominated by the effect of viscosity. On the contrary, for high Rayleigh number values $\left(\mathrm{Ra} \geq 10^{5}\right)$, the upward force becomes more important and the nanofluid circulates faster than the pure fluid (water). It is also noticeable that the shape of the isotherms highlights the change in the heat transfer mode when the Rayleigh number increases. Indeed, for $\mathrm{Ra}=10^{3}$, the isotherms are almost vertical due to the dominance of the heat conduction mode. In addition, by increasing the Rayleigh number, the dominance of heat transfer shifts from conduction to convection. For $\mathrm{Ra}=10^{6}$, the thermal field is marked by an almost horizontal stratification inside the cavity and consequently an enhancement of heat transfer in the vicinity of the active walls.

Figure 7 illustrates the isotherms (right) and the streamlines (left) for different Rayleigh numbers in the case of the base fluid $(\varphi=0 \%)$ and those of nanofluid $(\varphi=5 \%)$ in the $Z=0.5$ plane. For the flow lines (left), the pattern clearly shows that the streamlines are characterized by the presence of two cells bicellular and symmetrical with respect to the median plane in $X=0.5$. The formation of two contrarotating cells are also observed. The current lines have a shape that tends to deform when Rayleigh number is increased. In the temperature field (right), we notice that for moderate Rayleigh numbers, $\mathrm{Ra} \leq 10^{4}$ where viscous forces are more dominant than buoyancy forces and diffusion is the main mode of heat transfer, the thermal gradients are weak in the vicinity of the active walls. In the case of $\mathrm{Ra} \geq 10^{5}$, the figure shows that isotherms are strongly affected by the Rayleigh number. In addition, a dominant convection is noticed for the high Rayleigh number $\left(\mathrm{Ra}=10^{6}\right)$ with stratified thermal boundary layers close to the active walls.

The variation of nondimensional vertical velocity $W$ and horizontal velocity $U$ along the $Y$ direction for $\mathrm{Ra}=10^{3}, 10^{6}$ is presented in Figure 8. The profiles of the dimensionless velocity components $(U)$ and $(W)$ along the enclosure are presented in various locations. For $\mathrm{Ra}=10^{3}$, all profiles show a null velocity in the middle plane $Z=0.5$ and $X=$ 0.5 which is due to the velocity gradients noted for small $X$ and $Z$ distances. The velocity values are much higher than those observed near the upper wall characterized by high $X$ and $Z$ values because the fluid in the lower part of the main vortex has to pass through a smaller region. Furthermore, the velocity profiles show a maximum point at $X=0.2$ and $Z=0.2$. The role of the rear wall in this case is only to reduce the velocity magnitude for $Y=0.05$ due to viscous effects; nevertheless, there is no significant change in the profiles shape. For $10^{6}$, the influence of the rear walls is obvious. The temperature profiles shown in Figure 7 indicate that the effect of the rear wall on the velocity curves beside the wall of the heat source is greater. 

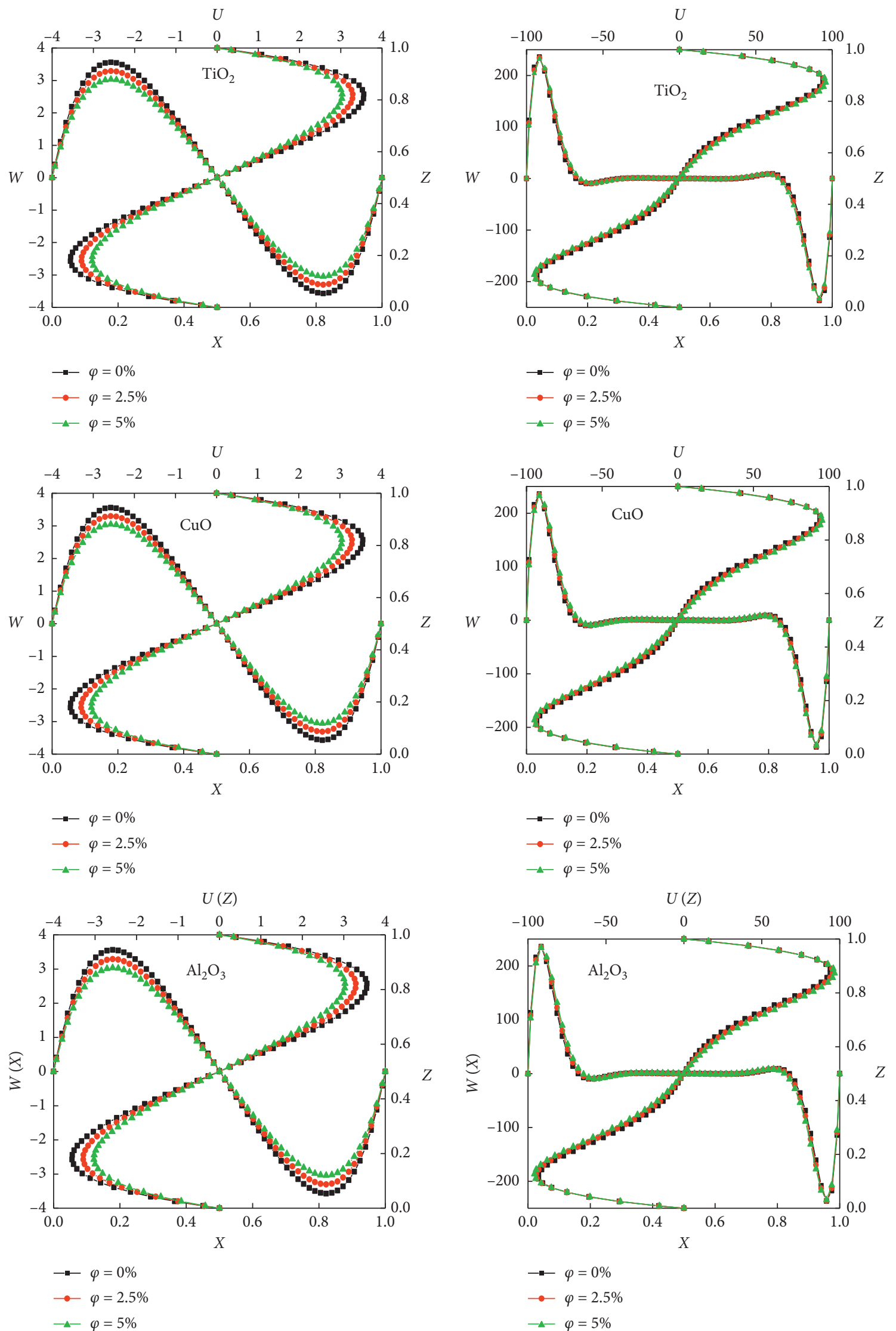

Figure 9: Velocity profiles $U(Z)$ and $W(X)$ through a centre of the $Y=0.5$ plane versus the volume fraction of the nanoparticles for right row $\mathrm{Ra}=10^{3}$ and left row $10^{6}$. 

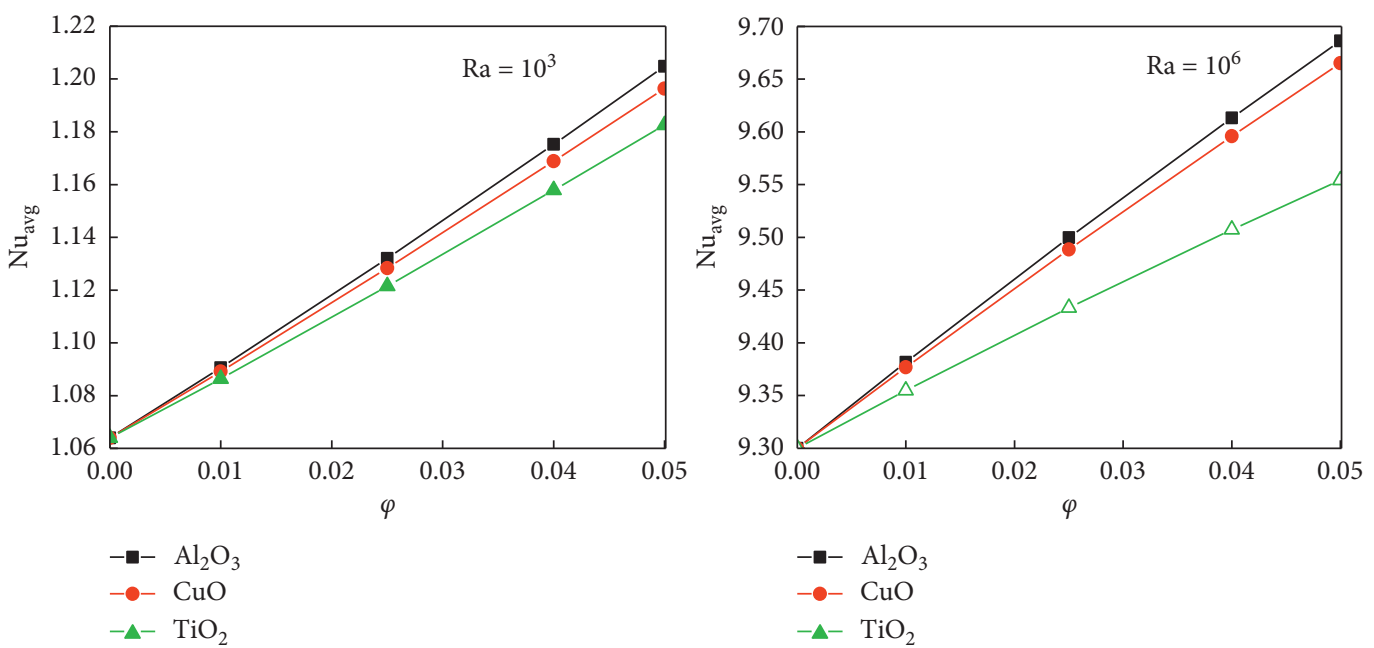

FIgURE 10: Evolution of $\mathrm{Nu}_{\text {avg }}$ as a function of $\varphi$ for $\mathrm{Ra}=10^{3}$ and $\mathrm{Ra}=10^{6}$.
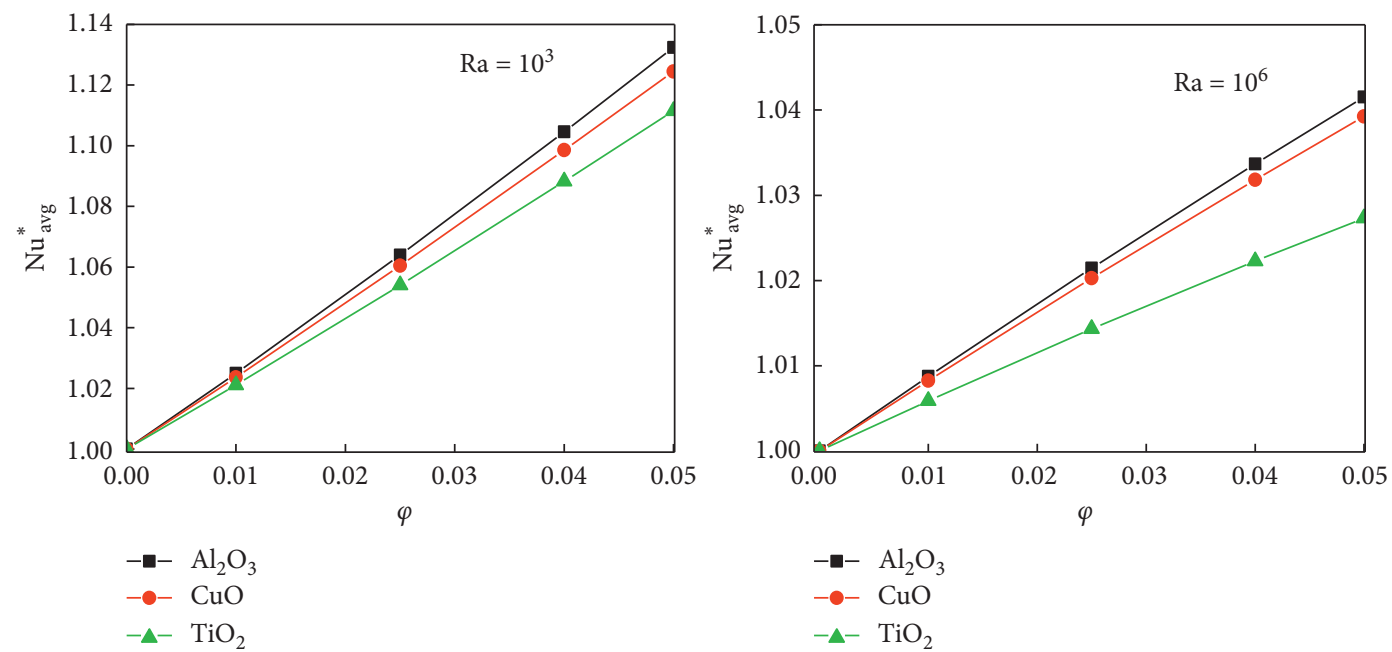

Figure 11: Evolution of $\mathrm{Nu}^{*}{ }_{\text {avg }}$ as a function of $\varphi$ for $\mathrm{Ra}=10^{3}$ and $\mathrm{Ra}=10^{6}$.

4.1. Effect of Different Nanoparticles Types. Figure 9 presents the specific profiles for the $X$ component of velocity $U$ and $Z$ component of velocity $W$ for water- $\mathrm{TiO}_{2}$, water- $\mathrm{CuO}$, and water- $\mathrm{Al}_{2} \mathrm{O}_{3}$ nanofluid at midsection of the cavity $Y=0.5$ for $\mathrm{Ra}=10^{3}$ and $10^{6}$ and for three values of nanoparticles volume fractions $\varphi_{n f}(0 \%, 2.5 \%$, and $5 \%)$. In case of a dominant conduction $\left(R a=10^{3}\right)$, it should be noted that the water achieves the highest velocities, while the addition of solid nanoparticles delays the flow. Consequently, the decrease in velocity leads to a lower convective heat transfer. However, since the heat regime is transported mainly by conduction, the diminution caused by a lower velocity is nearly small, and the overall heat transfer of the nanofluid is very important due to the greater thermal conductivity of the nanofluid. In the cases of greater Rayleigh number $\mathrm{Ra}=10^{6}$ when convection is dominated, we notice that the velocities reached by the nanofluid are higher to those of pure water, and therefore, an enhancement of heat transfer is obtained. In the event that convection dominates, the relative increase of heat transfer is smaller than that of conduction dominated case. Since, the increase in thermal conductivity is not a critical parameter of heat transfer when convection is dominant. In addition, by comparing velocity profiles between nanofluids water- $\mathrm{TiO}_{2}$, water- $\mathrm{CuO}$, and water- $\mathrm{Al}_{2} \mathrm{O}_{3}$, only a slight difference was noticed.

In order to allow a wider comparison, Figure 10 shows the variation in average Nusselt numbers with the volume fraction for various Ryleigh number. It is seen that the $\mathrm{Nu}_{\mathrm{avg}}$ raises straightly at high volume fraction for both nanofluids, revealing a better heat transfer situation. It is noticed also from the plots that maximum and minimum rate of heat transfer occurs for $\mathrm{Al}_{2} \mathrm{O}_{3}$-water and $\mathrm{TiO}_{2}$-water nanofluid, respectively.

Figure 11 represents the normalized average Nusselt number $N u_{\text {avg }}^{*}$ at $\mathrm{Ra}=10^{3}$ and $10^{6}$ to demonstrate the heat transfer efficacy of the nanofluids at different nanoparticles volume fractions $\varphi$. By comparing to the base fluid, the average Nusselt number of nanofluids with $1 \%$ of volume fraction of $\mathrm{TiO}_{2}, \mathrm{CuO}$, and $\mathrm{Al}_{2} \mathrm{O}_{3}$ nanoparticles increases by $2 \%, 2.1 \%$, and $2.3 \%$, respectively, for $\mathrm{Ra}=10^{3}$, whereas it 


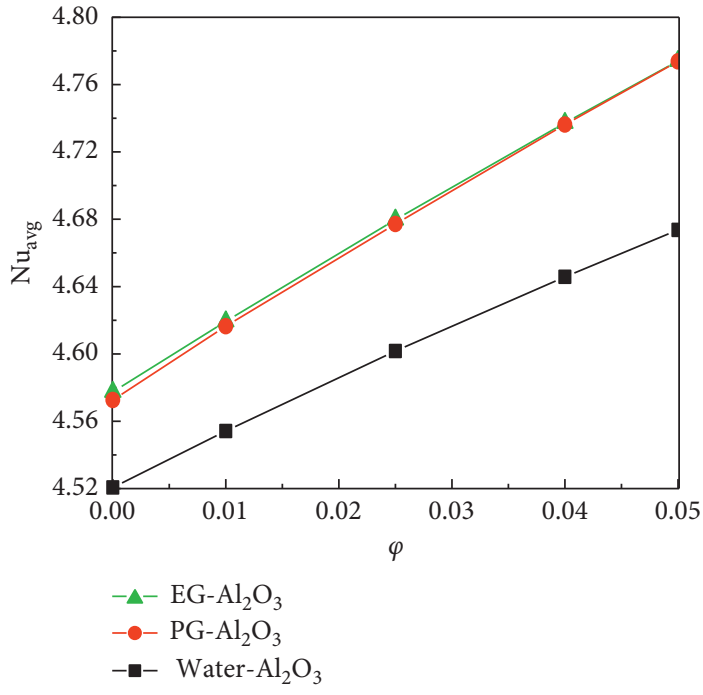

(a)

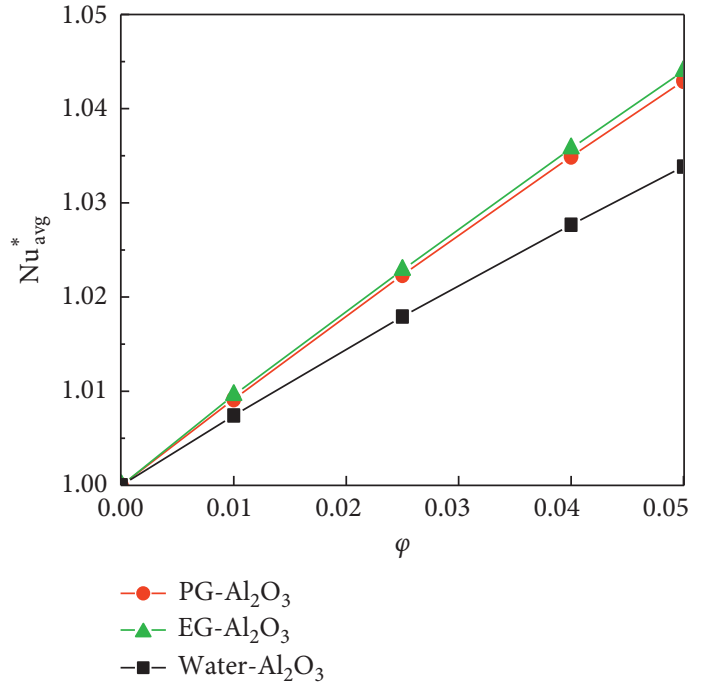

(b)

Figure 12: (a) Evolution of (a) $\mathrm{Nu}_{\text {avg }}$ and (b) $\mathrm{Nu}^{*}$ avg as a function of $\varphi$ for $\mathrm{Ra}=10^{5}$.


FIGURE 13: Evolution of $\mathrm{Nu}_{\text {avg }}$ as a function of $\varphi$ for $\mathrm{Ra}=10^{3}$ and $\mathrm{Ra}=10^{6}$.

increases by $0.7 \%, 0.4 \%$, and $0.6 \%$ for $\mathrm{Ra}=10^{6}$. An increase of nanoparticles volume fractions from $1 \%$ to $5 \%$ shows an enhancement of heat transfer which can reach $40 \%$. These statements indicate that the selected nanoparticles types have a paramount effect on the convective heat transfer applications.

4.2. Effect of the Base Fluid. The effects of the base fluid on the average Nusselt number are shown in Figure 12(a). For $\mathrm{Ra}=10^{5}$, the ethylene glycol- $\mathrm{Al}_{2} \mathrm{O}_{3}$ has the highest value of Nusselt number followed by propylene glycol- $\mathrm{Al}_{2} \mathrm{O}_{3}$, while the water- $\mathrm{Al}_{2} \mathrm{O}_{3}$ has the lowest value of the average Nusselt number. In addition, the presence of $\mathrm{Al}_{2} \mathrm{O}_{3}$ nanoparticle in ethylene glycol and propylene glycol enhances greatly the heat transfer compared to water. This is because glycols have higher dynamic viscosity compared to water. The influence of volume fractions on the average Nusselt number of $\mathrm{Al}_{2} \mathrm{O}_{3}$ nanoparticle of different base fluids is shown in Figure 12(b). The Nusselt number increases by about $3.4 \%$ for water$\mathrm{Al}_{2} \mathrm{O}_{3}$, almost $4.4 \%$ for propylene glycol- $\mathrm{Al}_{2} \mathrm{O}_{3}$ and finally $4.5 \%$ for ethylene glycol- $\mathrm{Al}_{2} \mathrm{O}_{3}$.

4.3. Effect of Mixtures Water-EG- $\mathrm{Al}_{2} \mathrm{O}_{3}$ and Water-PG- $\mathrm{Al}_{2} \mathrm{O}_{3}$. Figure 13 shows the variation of the average Nusselt number as a function of nanoparticles volume fractions of $\mathrm{Al}_{2} \mathrm{O}_{3}$ for two liquid mixtures (ethylene glycol-water and propylene glycol-water) as a base fluid at $\mathrm{Ra}=10^{3}$ and $10^{6}$. It can be seen that the average Nusselt number $N u_{\text {avg }}$ increases with 
the volume fraction of the nanoparticles. This increase is due to the improvement of the effective thermal conductivity of the nanofluid. The effect of the base fluid is significant on the variation of the average Nusselt $N u_{\text {avg }}$, displaying a better rate of heat transfer for ethylene glycol-water- $\mathrm{Al}_{2} \mathrm{O}_{3}$ compared to propylene glycol-water- $\mathrm{Al}_{2} \mathrm{O}_{3}$. The mixture allows for stronger heat exchange, which is favored by higher conductivity for heat removal, lower heat capacity for reduced storage, and higher density for convection.

\section{Conclusion}

In the present study, the thermal and flow field natural convection fluid flow and heat transfer of three nanofluids $\mathrm{Al}_{2} \mathrm{O}_{3}, \mathrm{CuO}$, and $\mathrm{TiO}_{2}$ in $3 \mathrm{D}$ cubical enclosure were investigated numerically using the finite volume methodbased SIMPLEC algorithm. The effects of nanoparticle types, volume fraction, and the type of the base fluid are analysed. The major comparative results are briefly summarized as follows:

(i) Heat transfer improvement is obtained for nanofluid with $\mathrm{Al}_{2} \mathrm{O}_{3}$ followed by $\mathrm{CuO}$ and $\mathrm{TiO}_{2}$. An enhancement of $13 \%$ is obtained for $\mathrm{Al}_{2} \mathrm{O}_{3}$-EG in comparison to pure ethylene glycol in the case of $\mathrm{Ra}=10^{3}$.

(ii) With the increase of the Rayleigh number, heat transfer becomes more pronounced in the case of dominant heat convection

(iii) The heat transfer enhancement is observed with the rise of nanoparticle volume fractions to the base fluid

(iv) A better rate of heat transfer is displayed for ethylene glycol-water- $\mathrm{Al}_{2} \mathrm{O}_{3}$ compared to propylene glycol-water- $\mathrm{Al}_{2} \mathrm{O}_{3}$

\section{Abbreviations}

$C_{P}: \quad$ Specific heat at constant pressure $\left(\mathrm{J} \cdot \mathrm{kg}^{-1} \mathrm{~K}^{-1}\right)$

$G: \quad$ Gravitational acceleration $\left(\mathrm{m} \mathrm{s}^{-2}\right)$

$H$ : $\quad$ Local heat transfer coefficient $\left(\mathrm{W} \cdot \mathrm{m}^{-2} \mathrm{~K}^{-1}\right)$

$H: \quad$ Dimension of the cubic cavity $(\mathrm{m})$

K: $\quad$ Thermal conductivity $\left(\mathrm{W} \cdot \mathrm{m}^{-1} \mathrm{~K}^{-1}\right)$

Nu: $\quad$ Nusselt number

$P: \quad$ Pressure $(\mathrm{Pa})$

$P: \quad$ Dimensionless pressure

Pr: $\quad$ Prandtl number

$\widehat{R}_{N}^{\varnothing}$ : $\quad$ Normalised global residual

Ra: Rayleigh number

T: $\quad$ Temperature (K)

$T_{H}$ : Temperature of hot wall (K)

$T_{C}$ : $\quad$ Temperature of cold wall $(\mathrm{K})$

$u, v, \mathrm{w}: \quad$ Velocity components $\left(\mathrm{ms}^{-1}\right)$

$\mathrm{U}, \mathrm{V}, \mathrm{W}$ : Dimensionless velocities

$\mathrm{x}, y, \mathrm{z}: \quad$ Cartesian coordinate $(\mathrm{m})$

$\mathrm{X}, \mathrm{Y}, \mathrm{Z}$ : Dimensionless cartesian coordinates

$\alpha: \quad$ Thermal diffusivity $\left(\mathrm{m}^{2} . \mathrm{s}^{-1}\right)$

$\beta$ : $\quad$ Thermal expansion coefficient $\left(\mathrm{K}^{-1}\right)$

$\varphi: \quad$ Volume fraction of nanoparticles

$\begin{array}{ll}\varnothing: & \text { Independent variable } \\ \mu: & \text { Dynamic viscosity }\left(\mathrm{kg} \cdot \mathrm{m}^{-1} \cdot \mathrm{s}^{-1}\right) \\ \vartheta: & \text { Kinematic viscosity }\left(\mathrm{m}^{2} \cdot \mathrm{s}^{-1}\right) \\ \psi: & \text { Stream function } \\ \rho: & \text { Density }\left(\mathrm{kg} / \mathrm{m}^{3}\right) \\ \Theta: & \text { Dimensionless temperature } \\ \text { Avg: } & \text { Average } \\ f: & \text { Base fluid } \\ m: & \text { Mixture } \\ \mathrm{nf}: & \text { Nanofluid } \\ p: & \text { Particle. }\end{array}$

\section{Data Availability}

The data used to support the findings of this study are available from the corresponding author upon request.

\section{Conflicts of Interest}

The authors declare that they have no conflicts of interest.

\section{References}

[1] S. Ostrach, "Natural convection in enclosures," Journal of Heat Transfer, vol. 110, no. 4b, pp. 1175-1190, 1988.

[2] U. S. Choi, "Enhancing thermal conductivity of fluids with nanoparticles," in Developments and Applications of NonNewtonian Flows, D. A. Signer and H. P. Wang, Eds., vol. 66, pp. 99-105, ASME, New York, NY, USA, 1995.

[3] Y. Li, J. e. Zhou, S. Tung, E. Schneider, and S. Xi, "A review on development of nanofluid preparation and characterization," Powder Technology, vol. 196, no. 2, pp. 89-101, 2009.

[4] W. Yu and H. Xie, "A review on nanofluids: preparation, stability mechanisms, and applications," Journal of Nanomaterials, vol. 2012, p. 17, Article ID 435873, 2012.

[5] A. Asadi, "A guideline towards easing the decision-making process in selecting an effective nanofluid as a heat transfer fluid," Energy Conversion and Management, vol. 175, pp. 1-10, 2018.

[6] K. Khanafer, K. Vafai, and M. Lightstone, "Buoyancy-driven heat transfer enhancement in a two-dimensional enclosure utilizing nanofluids," International Journal of Heat and Mass Transfer, vol. 46, no. 19, pp. 3639-3653, 2003.

[7] R. Mohebbi, M. Izadi, and A. J. Chamkha, "Heat source location and natural convection in a C-shaped enclosure saturated by a nanofluid," Physics of Fluids, vol. 29, no. 12, Article ID 122009, 2017.

[8] S. A. M. Mehryan, M. Ghalambaz, A. J. Chamkha, and M. Izadi, "Numerical study on natural convection of Ag-MgO hybrid/water nanofluid inside a porous enclosure: a local thermal non-equilibrium model," Powder Technology, vol. 367, pp. 443-455, 2020.

[9] M. Ghalambaz, A. Doostani, E. Izadpanahi, and A. J. Chamkha, "Conjugate natural convection flow of Ag$\mathrm{MgO} /$ water hybrid nanofluid in a square cavity," Journal of Thermal Analysis and Calorimetry, vol. 139, no. 3, pp. 23212336, 2020.

[10] M. A. Mansour, S. E. Ahmed, and A. M. Rashad, "MHD natural convection in a square enclosure using nanofluid with the influence of thermal boundary conditions," Journal of Applied Fluid Mechanics, vol. 9, no. 7, pp. 2515-2525, 2016.

[11] E. A. Sameh, M. A. Mansour, A. M. Rashad, and T. Salah, "MHD natural convection from two heating modes in fined 
triangular enclosures filled with porous using nanofluids," Journal of Thermal Analysis and Calorimetry, vol. 139, pp. 3133-3149, 2020.

[12] M. Ghalambaz, A. J. Chamkha, and D. Wen, "Natural convective flow and heat transfer of Nano-Encapsulated Phase Change Materials (NEPCMs) in a cavity," International Journal of Heat and Mass Transfer, vol. 138, pp. 738-749, 2019.

[13] E. Tric, G. Labrosse, and M. Betrouni, "A first incursion into the 3D structure of natural convection of air in a differentially heated cubic cavity, from accurate numerical solutions," International Journal of Heat and Mass Transfer, vol. 43, no. 21, pp. 4043-4056, 2000.

[14] J. Ravnik, L. Skerget, and M. Hriberšek, "Analysis of threedimensional natural convection of nanofluids by BEM," Engineering Analysis with Boundary Elements, vol. 34, no. 12, pp. 1018-1030, 2010.

[15] P. Ternik, "Conduction and convection heat transfer characteristics of water-Au nanofluid in a cubic enclosure with differentially heated side walls," International Journal of Heat and Mass Transfer, vol. 80, pp. 368-375, 2015.

[16] M. Sannad, B. Abourida, L. Belarche, H. Doghmi, and M. Ouzaouit, "Effect of the heating block position on natural convection in a three-dimensional cavity filled with nanofluids," Journal of Applied Fluid Mechanics, vol. 12, no. 1, pp. 281-291, 2019.

[17] E. Abu-Nada and A. J. Chamkha, "Effect of nanofluid variable properties on natural convection in enclosures filled with a CuO-EG-Water nanofluid," International Journal of Thermal Sciences, vol. 49, no. 12, pp. 2339-2352, 2010.

[18] H. F. Oztop and E. Abu-Nada, "Effect of inclination angle on natural convection in enclosure filled with $\mathrm{Cu}$-water nanofluids," International Journal of Heat Fluid Flow, vol. 30, pp. 669-678, 2009.

[19] A. Charif and A. Daif, "Etude numerique du transfert de chaleur et de masse entre deux plaques planes verticales en présence d'un film de liquide binaire ruisselant sur l'une des plaques chauffée," International Journal of Heat and Mass Transfer, vol. 42, pp. 2399-2418, 1999.

[20] H. C. Brinkman, "The viscosity of concentrated suspensions and solutions," The Journal of Chemical Physics, vol. 20, no. 4, p. $571,1952$.

[21] J. C. Maxwell-Garnett, "Colours in metal glasses and in metallic films," Philosophical Transactions of the Royal Society A: Mathematical, Physical and Engineering Sciences, vol. 203, pp. 385-420, 1904.

[22] S. V. Patankar, Numerical Heat Transfer and Fluid Flow, Hemisphere, New York, NY, USA, 1980.

[23] J. D. Hoffman, Numerical Methods for Engineers and Scientists, Markel Dekker Inc., New York, NY, USA, second edition, 2001.

[24] T. Fusegi, J. M. Hyun, K. Kuwahara, and B. Farouk, "A numerical study of three-dimensional natural convection in a differentially heated cubical enclosure," International Journal of Heat and Mass Transfer, vol. 34, no. 6, pp. 1543-1557, 1991.

[25] Y. Peng, C. Shu, and Y. T. Chew, "A 3D incompressible thermal lattice Boltzmann model and its application to simulate natural convection in a cubic cavity," Journal of Computational Physics, vol. 193, pp. 260-274, 2003.

[26] D. C. Lo, D. L. Young, and K. Murugesan, "GDQ method for natural convection in a cubic cavity using velocity-vorticity formulation," Numerical Heat Transfer, Part B: Fundamentals, vol. 48, no. 4, pp. 363-386, 2005. 